\title{
Study on axial compression ratio of Seismic Performance of Steel Tube Filled with Steel-reinforced Concrete Composite Column
}

\author{
Bing Wang ${ }^{1, a},{ }^{*}$ Xiao Liu ${ }^{1, b}$, Pan Ren ${ }^{1, c}$ \\ ${ }^{1}$ School of Architectural and Civil Engineering, Shenyang University, Shenyang, 110044, China \\ aliuxiao19740701@sina.com, b489298344@qq.com , c494644251@qq.com \\ *Corresponding author: Professor Xiao Liu, School of Architectural and Civil Engineering, \\ Shenyang University, Shenyang, 110044, China \\ Tel: 8610 62721531, E-mail address: 494644251@qq.com
}

Keywords: STFSC; composite column; axial compression ratio; seismic performance Abstract: With the rapid development of cities, the building becoming larger and higher. That means the weight of building will increase, the disaster will cause a greater loss. Bearing column is the main stress components of building, determining the safety of the building under earthquake. Steel Tube Filled with Steel-reinforced Concrete Composite Column(STFSC) has the advantages of concrete-filled steel tube column and steel reinforced concrete column. Therefore, this paper study on axial compression ratio of seismic performance of STFSC by ABAQUS finite element analysis software

\section{Introduction}

The tensile, compressive and bending performance of steel is good, but fireproof performance and corrosion resistance is poor, concrete has good compressive strength and refractory performance, but the bending performance is not good. The steel tube filled with concrete can enhance the stability of the steel pipe, avoid ing the bearing capacity of steel pipe reducing after fire. Concrete compressed by more direction improves the concrete compressive strength, deformation capacity and component impact resistant ability, and improve the performance of fire resistance and corrosion. Besides steel tube can be used as the template to improve speed of construct. The present study as follows: (1) Guan Ping, Wang qing-xiang, Zhao da-zhou [1-3] study on the seismic performance of STFSC which built-in cross-shaped steel, studying its failure pattern, bearing capacity through the experiment. (2)Xu ya-feng, Zhao Jingyi [4-7] study the seismic performance of STFSC which steel bone outside and steel built-in, getting the hysteresis loop of different axial compression ratio and different gravel ratio. (3) Zhu Meichun jian-xin liu, qingxiang wang [8] take intensity of concrete, axial compression ratio as the parameters, studying the square steel tube reinforced concrete composite column with built-in i-section and crossshaped steel and the seismic performance of steel tests. Now there are little researchers study on seismic performance research of STFSC embedded I-section steel. Therefore, this article study on axial compression ratio of seismic performance of STFSC. 


\section{Related Parameters}

Component parameters. This article will discuss the effect of axial compression ratio to the seismic performance of STFSC. The length of component are $1000 \mathrm{~mm}$. Concrete compressive strength is $70[\mathrm{MPa}]$.

Table 1 component parameters

\begin{tabular}{cccccc}
\hline Number & D $\times \mathrm{t}[\mathrm{mm}]$ & $f_{c k}[\mathrm{MPa}]$ & $f_{t y}[\mathrm{MPa}]$ & $f_{s y}[\mathrm{MPa}]$ & Axial compression ratio \\
\hline Z-1 & $220 \times 3$ & 70 & 235 & 235 & 0 \\
Z-2 & $220 \times 3$ & 70 & 235 & 235 & 0.4 \\
Z-3 & $220 \times 3$ & 70 & 235 & 235 & 0.8 \\
\hline
\end{tabular}

D、 t- Steel pipe diameter and thickness; $f_{c k}, f_{t y}, f_{s y}$ - compressive strength of concrete, steel bone and yield strength of steel pipe。

Loading system. Loading controlled by displacement to determine the components mechanical properties in different displacement condition. We should make sure the yield displacement values under horizontal load before applying cyclic loading. The yield displacement is about 4 $\mathrm{mm}$ through simulation. Loading controlled by level-to-level displacement before yield; Difference reduce to $0.5 \mathrm{~mm}$ when close to the yield and increase to $1 \mathrm{~mm}$ after yield. Loading system is shown in figure 1.

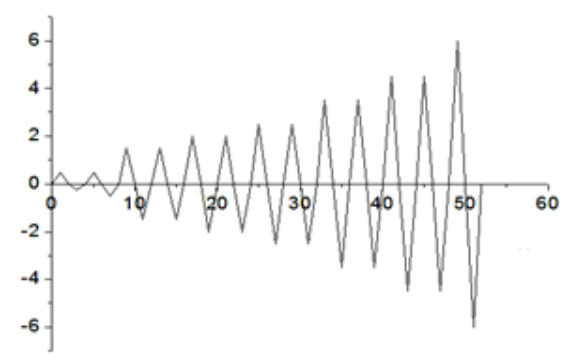

Fig 1 the loading system

\section{Axial Compression Ratio Analysis}

Hysteresis loop. Hysteresis loop is the relationship of displacement and load conducted by component under repeated loading. Hysteresis loop has four basic forms as shown in table 2:

For STFSC, concrete compressed from three direction, steel tube confined concrete development, the bone steel inhibit the concrete appear cracks and development. At the same time, the existence of the concrete enhance the stability of the whole component. Therefore, Hysteresis loop of STFSC likes spindle. The loop is full, indicating good seismic performance. 
Table 2 the form of the hysteresis loop

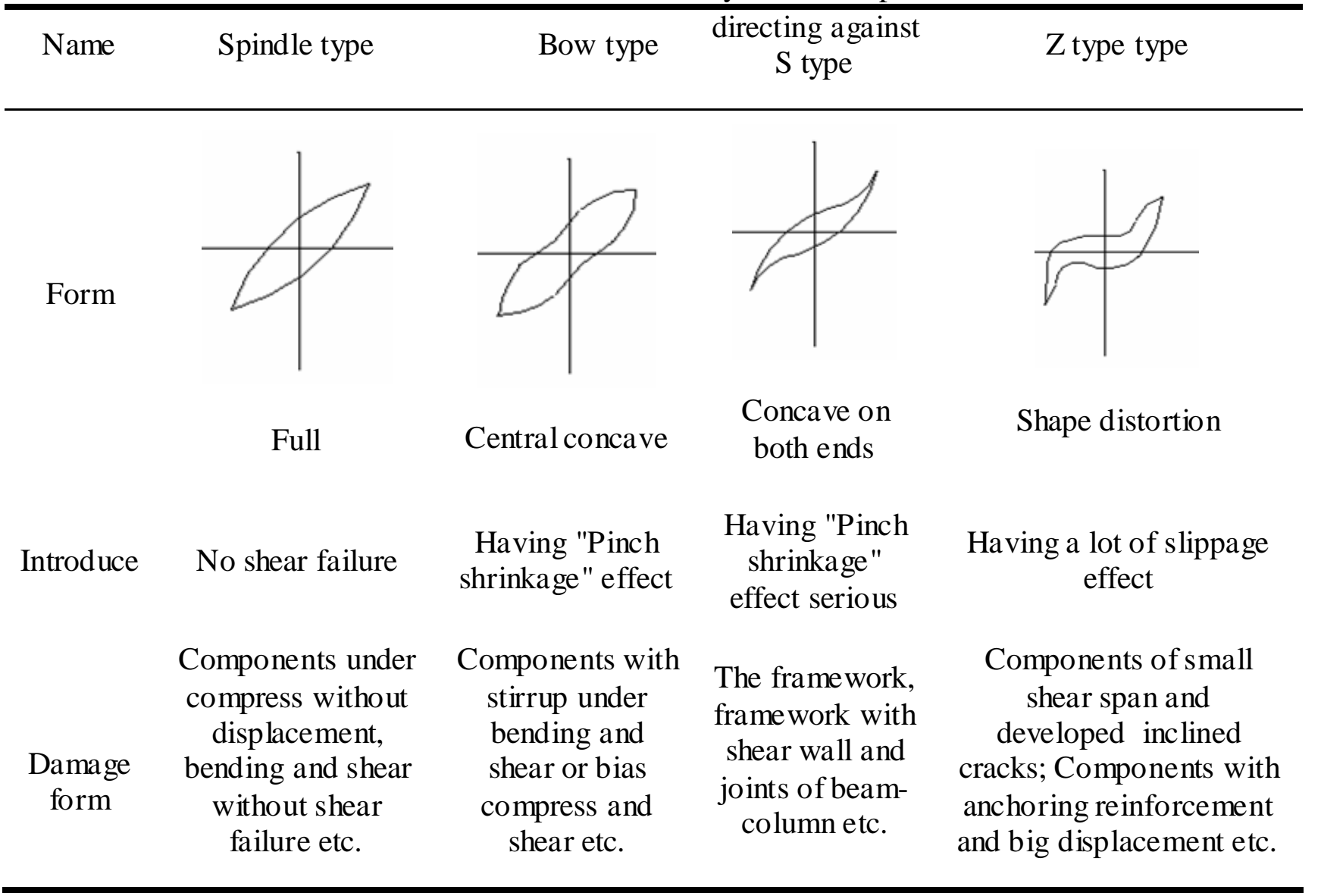

\section{Hysteresis loop in different axial compression ratio}

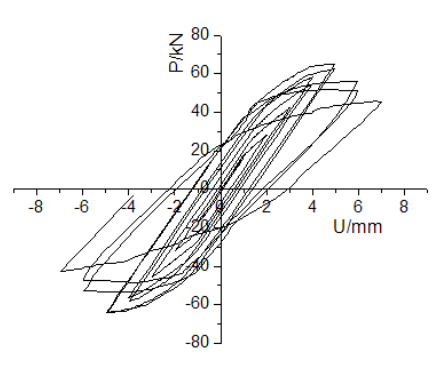

$\mathrm{n}=0$

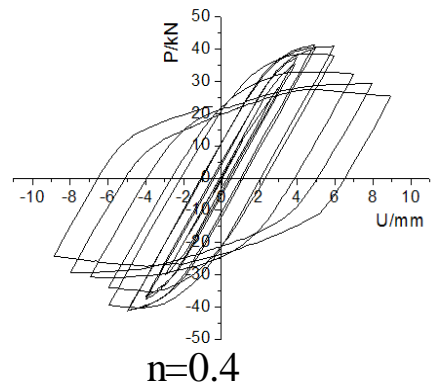

$\mathrm{n}=0.4$

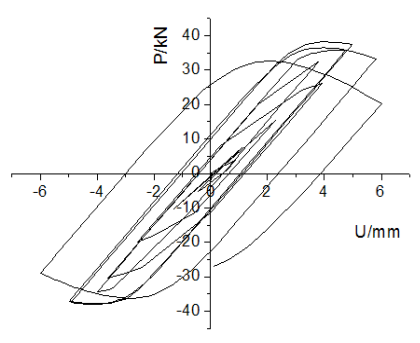

$\mathrm{n}=0.8$

Fig 2 the hysteresis loop of different axial compression ratio

We can know from the hysteresis loop of different axial compression ratio, the hysteresis loop of the smallest Axial compression is most full, almost present standard spindle, that show the strongest energy consumption. The curve is more gentle after component reach maximum, that show good ductility. The hysteresis loop appear the trend of directing against $\mathrm{S}$ with the increase of axial compression ratio.

Under the repeated cyclic loading, the area of the hysteresis loop show components absorbed energy after repeated loading. We can found the area of Hysteresis loop is increasing in the hysteresis loop. This means that energy consumption capacity of components is increased. The energy consumption capacity of components is good. 


\section{Conclusion}

This article selects axial compression ratio as the parameters, Study on axial compression ratio of STFSC:

1、The hysteresis loop of each component is full, no obvious pinch phenomenon, show a good ability of energy dissipation and plastic deformation. Axial compression ratio change will affect the shape of the hysteresis curve and carrying capacity.

2、 The area of hysteresis loop show the ability of energy consumption. With axial compression ratio increasing, the capacity of the energy dissipation reduce.

\section{Acknowledgement}

It is a project supported by National Science Foundation (51308347).

It is a project supported by Shenyang Science Plan project (F13-171-9-00).

It is a project supported by Shenyang Science Plan project (F14-028-2-00)

It is a project supported by Shenyang Science Plan project(F14-210-6-00)

It is a project supported by Liaoning science public research funds(2014004025)

\section{Reference}

[1] Guan Ping, Wang Qing-xiang, Zhao Da-zhou. Experimental research on mechanical behavior of bending circular steel tube columns filled with steel-reinforced concrete[J]. Earthquake engineering and Engineering Vibration. 2003,02:57-60

[2] Guan Ping, Wang Qing-xiang, Zhao Da-zhou. Experimental study on ductility of circular steel tubular columns filled with steel-reinforced concrete[J]. Earthquake engineering and Engineering Vibration,2003,01:84-89.

[3] Guan Ping, Wang Qing-xiang, Zhao Da-zhou. Study on ductility of circular steel tubular columns filled with axial compressive ratio [J]. Journal of Dalian University, 2003,02:32-34+65.

[4] Zhao Jingyi, Xu Yafeng. Study on ductility of circular steel tubular columns filled with steelreinforced concrete and restoring force [A]. Tianjin University, 2008:6.

[5] Xu Ya feng, Zhao Jingyi, Li Ning, Lu Xiaoyi.Studies on Restoring Force Model of Circular Steel Tube Composite Column Filled with Steel Reinforced Concrete[J]. Journal of Shenyang Jianzhu University(Natural Science), 2009,03:482-485.

[6] Xu Ya feng, Zhao Jingyi,Liu Na.The Ductility Analysis of Circular Steel Tube Compile Column Filled with Steel Reinorced Concrete on Cyclic Loading[J]. Journal of Shenyang Jianzhu University(Natural Science), 2009,04:689-693.

[7] Xu Ya-feng, Zhao Jing-yi, Zhang Shi-xian, Lu Xiao-yi. Experimental Research on Seismic Behavior of Circular Steel Tube Composite Column Filled with Steel Reinforced Concrete[J]. Progress in Steel Building Structures, ,2009,03:4-11. 
[8] Zhu Meichun, Liu Jianxin,Wang Qingxiang. Experimental study of seismic behavior of square steel tubes filled with steel-reinforced high-strength concrete[J].China Civil Engineering Journal, 2011, (7):55-63. 